\section{Use of high speed centrifugation in early detection of bacteraemia}

\author{
A W STURM From the Department of Medical Micro- \\ biology, St Laurentius Hospital, The Netherlands
}

The incidence of bacteraemia, one of the most serious conditions in clinical microbiology, is increasing due to advances in clinical medicine such as immunosuppressive treatment, sophisticated surgery, and the possibility of treating many previously fatal conditions. In these cases the value of a positive blood culture is relative to the speed of reporting, and many published reports deal with technical advances in this field. These include reports on semiautomated radiometric techniques, ${ }^{1}$ blood culture slide systems, ${ }^{2}$ fluorochrome stained smears, ${ }^{3}$ incubation and subculture timing, ${ }^{4}$ and lysis-centrifugation. ${ }^{5}$ In an attempt to decrease reporting time using a conventional broth culture system I studied the influence of high speed centrifugation on the results of the microscopic detection of positive blood cultures.

\section{Material and methods}

Five $\mathrm{ml}$ of blood was taken aseptically using a sterile blood collecting tube (Curapharm, Medica Hospital Supplies, Hertogenbosch, The Netherlands) into each bottle of a blood culture set, comprising one bottle of $95 \mathrm{ml}$ Columbia broth (CB, BBL Microbiology systems, Cockeysville, Md, United States of America) and one with $80 \mathrm{ml}$ brain heart infusion broth (BHI, Difco Laboratories, Detroit, Michigan). Both were supplemented with $2 \cdot 5 \%$ yeast dialysate, $1 \%$ cysteine, and $0.025 \%$ sodium polyanethol sulfonate. After inoculation the second bottle was vented and both were incubated at $37^{\circ} \mathrm{C}$. Blood sampling between 6.00 pm and 2.00 am was followed by microscopy after six to 12 hours at 8.00 am the next morning. A second microscopic examination and the first subculture was done at $4.00 \mathrm{pm}$ followed by a second set of subcultures the next morning at $8.00 \mathrm{am}$. From the third to tenth day after blood sampling the bottles were examined macroscopically twice daily at 8.00 am and 5.00 $\mathrm{pm}$. On the eighth day a last set of subcultures was done. If blood sampling occurred between $11.30 \mathrm{am}$ and $6.00 \mathrm{pm}$ the same scheme was followed with the exception of those cases in which the clinician asked for immediate processing; then the first microscopy was done six hours after sampling. If blood was taken

Accepted for publication 14 May 1986 between 2.00 and $11.30 \mathrm{am}$, first handling was done at about $5.30 \mathrm{pm}$, the second on the following morning at about $8.00 \mathrm{am}$, and the third at about $4.00 \mathrm{pm}$. Processing during the last eight days was similar, regardless of initial examination methods.

Clinical evaluation of positive cultures was done by the author, based on culture results of other specimens, patients' history, and, if necessary, discussion with the clinician.

\section{Results}

In this manner 5003 blood cultures from 2815 patients were processed in a 4.75 year period. Of these cultures, $23.3 \%$ yielded bacteria: $834(16.7 \%)$ were judged as clinically important, and $331(6.6 \%)$ as contamination. Of the contaminated cultures, $102(2.0 \%$ of the total) were collected by a laboratory technician from the author's laboratory, but in 229 cases $(4.6 \%$ of the total) blood sampling was done by a more or less experienced nurse or a member of the junior medical staff outside normal working hours. The time between blood sampling and first detection and reporting of bacteraemia is summarised in the table: $74.5 \%$ were found in less than 18 hours and $86 \%$ within 42 hours. The highest percentages of positive cultures after six to twelve hours of incubation were found with Streptococcus pneumoniae $(63 \%)$, haemolytic streptococci from different Lancefield groups $(64 \%)$, enterococci $(59 \%)$, Escherichia coli $(64 \%)$ and clostridia $(60 \%)$.

\section{Discussion}

Centrifugation at $3000 \times g$ as a concentration method for bacteria in blood cultures was first used as part of the lysis centrifugation method by Dorn et al. ${ }^{5}$ With this method some negative cultures were obtained from specimens that had been positive in the conventional broth system and vice versa. ${ }^{5}$ Because of this and the need for a special centrifugation device, ${ }^{5}$ I tried to improve the broth blood culture system by centrifugation after various incubation intervals, instead of centrifugation with lysis before incubation.

Because of variation in detection time between the groups of bacteria in artificial blood cultures, with a standard inoculum at the start (unpublished data), differences in detection time in blood culture systems can only be judged if the rates of isolated species are comparable. Percentages of positive cultures detected within 24 hours after blood sampling vary between 53 and $76 \%,{ }^{1-4}$ but unfortunately, in many studies no information on the numbers of isolated strains of each bacterial species has been given. In this study 
Table No (cumulative \%) of positive blood cultures from 566 patients with bacteraemia in relation to time between blood sampling and first reporting

\begin{tabular}{|c|c|c|c|c|c|c|}
\hline \multirow[b]{2}{*}{ Bacteria } & \multicolumn{5}{|c|}{ Time between blood sampling and reporting } & \multirow[b]{2}{*}{ Total No } \\
\hline & 6-12 hours & 13-18 hours & $19-42$ hours & 3-9 days & 10 days & \\
\hline $\begin{array}{l}\text { Staphylococci } \\
\text { Streptococci } \\
\text { Enterobacteria } \\
\text { Non-fermentative Gram } \\
\text { negative rods }\end{array}$ & $\begin{array}{r}75(32) \\
66(51) \\
202(58) \\
4(17)\end{array}$ & $\begin{array}{r}91(70) \\
47(81) \\
102(87) \\
9(54)\end{array}$ & $\begin{array}{r}36(86) \\
12(90) \\
18(92) \\
5(75)\end{array}$ & $\begin{array}{r}24 \\
8 \\
23 \\
2\end{array}$ & $\begin{array}{r}10 \\
6 \\
5 \\
4\end{array}$ & $\begin{array}{r}236 \\
139 \\
350 \\
24\end{array}$ \\
\hline $\begin{array}{l}\text { Fastidious Gram negative rods } \\
\text { Gram positive rods } \\
\text { Anaerobes } \\
\text { Total No }\end{array}$ & $\begin{array}{r}8(26) \\
6(40) \\
18(22) \\
379(43)\end{array}$ & $\begin{array}{c}8(52) \\
3(60) \\
14(40) \\
274(74 \cdot 5)\end{array}$ & $\begin{array}{l}3(61) \\
28(74 \cdot 5) \\
102(86)\end{array}$ & $\begin{array}{l}5 \\
5 \\
15 \\
82(95 \cdot 5)\end{array}$ & $\begin{array}{l}7 \\
1 \\
6 \\
39(100)\end{array}$ & $\begin{array}{r}31 \\
15 \\
81 \\
876\end{array}$ \\
\hline
\end{tabular}

$74.5 \%$ were found within 24 hours in a group of positive cultures, of which $16 \%$ contained slow growing organisms (table).

Microscopy has the advantage over subculturing in that if bacteria are detected a preliminary susceptibility test can be done. In this study the results of such a test could be read after another six to twelve hours in $74 \%$ of species. In this way the results of susceptibility testing could be reported within 36 hours of blood sampling in $60 \%$ of patients with clinically important bacteraemia.

The percentage of contaminated cultures sampled by experienced workers agreed with that of other workers $;{ }^{4}$ the much higher contamination figure for cultures taken by less experienced staff $^{4}$ also agreed with that of other workers. Compared with published data, the results of Gram staining and microscopy after centrifugation of $2 \mathrm{ml}$ samples at $3000 \times \mathrm{g}$ for five minutes detected clinically important bacteraemia as fast as more advanced and expensive culture methods. ${ }^{1-4}$
I thank Patrick Sturm and Petra Verstappen for their technical help.

\section{References}

1 Corkill JE. Effects of media, working practice, and automation on the rapid detection of bacteraemia. J Clin Pathol 1985;38:336-40.

2 Langmaak H, Gallien R. Untersuchungen über ein neues zeitund kostensparendes Blutkultursystem. Lab Med 1980;3:273-9.

3 Meseguer M, Rafael de L, Baquero M, Martinez Ferrer M, Lopez-Brea M. Acridine orange stain in the early detection of bacteria in blood cultures. Eur J Clin Microbiol 1084;3:113-15.

4 Youngs E, Roberts C. Earlier detection of bacteraemia using conventional microbiological techniques. $J$ Clin Pathol 1985;38:593-4.

5 Dorn GL, Land GA, Wilson GE. Improved blood culture technique based on centrifugation: clinical evaluation. $J$ Clin Microbiol 1979;9:391-96.

Requests for reprints to: Dr AW Sturm, Department of Medical Microbiology, St Laurentius Hospital, Postbox 920, 6040 AX Roermond, The Netherlands.

\section{Letters to the Editor}

\section{Plasma enzyme changes in carcinoma of bronchus mimicking myocardial infarction}

Patients with carcinoma may exhibit the presence of some rather unusual isoenzymes in circulating plasma. ${ }^{12}$ When these plasma enzyme activities change over time, however, diagnostic confusion may arise, as shown by the following case.

A 59 year old woman was admitted to the ear, nose, and throat unit after an episode of epistaxis. She collapsed in bed the same evening and complained of back and chest pain. She was transferred to a coronary care unit, where a tentative diagnosis of myocardial infarction was made. She had experienced chest discomfort in the recent past, and on this occasion the pain lasted longer and radiated to both arms.

An electrocardiogram showed no changes of acute ischaemia. There was $T$ wave inversion in V1 and 2 and some increase in ST in leads III and IV. A chest radiograph showed some cardiac enlargement, but there was no evidence of neoplastic disease there, or in the lumbar spine or pelvis.

The table shows her enzyme activity over the eight days after admission. Creatife kinase-B subunit activity (CK-B) measured quantitatively by the technique $\Theta f$ immunoinhibition (Boehringer, West Germany; No 300691). The pattern $\frac{7}{8} f$ enzyme changes over time were typical of those found after acute myocardigal infarction with a rise in creatine kinase and serum aspartase transferase (AST) and ${ }_{a}$ slower rise in $\alpha$-hydroxybutyrate dehydrogenase (HBD) activities. She veas treated for presumed myocardial infarctign with bed rest and cardiac monitorigg. Creatine kinase isoenzyme electrophoressis of the samples from days 2 and 3 thien showed the presence of both CK-MM and 